\title{
Origins, History, and Achievements of the World Health Organization
}

\author{
Sir JOHN CHARLES, * K.C.B., M.D., F.R.C.P., D.P.H.
}

Brit. med. F., 1968, 2, 293-296

A natural curiosity about the health of other countries combined at times with anxiety as to the movements of plague or other epidemic diseases has long been a feature of British medical history and sanitary policy.

In the early decades of the nineteenth century such concern about foreign pestilences was greatly intensified by the invasion of Europe by yellow fever, and later by the first of the epidemics of Asiatic cholera. Fears arising from cholera were shared by all the maritime states of Europe and by other countries further afield. They were largely responsible for the ten international sanitary conferences which met in various cities of Europe and once in Washington between 1851 and the end of the century. These conferences deliberated upon quarantine regulations which were to deal with plague, cholera, yellow fever, and " any other disease reputed to be importable." The usual governmental delegation was composed of one diplomat and one doctor, who were quite capable of differing inter se. For this and other reasons it is not surprising that the recommendations of the conferences were rarely accepted in full by governments.

Meanwhile, apart from these recurrent phenomena, certain countries in the near and middle east-Egypt, Turkey, and Persia-were establishing bodies of greater permanence which regulated so far as they could the sanitary and quarantine affairs of their areas. A comparable development on a continental jasis was the establishment in 1902 of the Pan American Sanitary Organization with its headquarters in Washington. The functions of this organization were also largely concerned with quarantine, but they were soon extended to include general

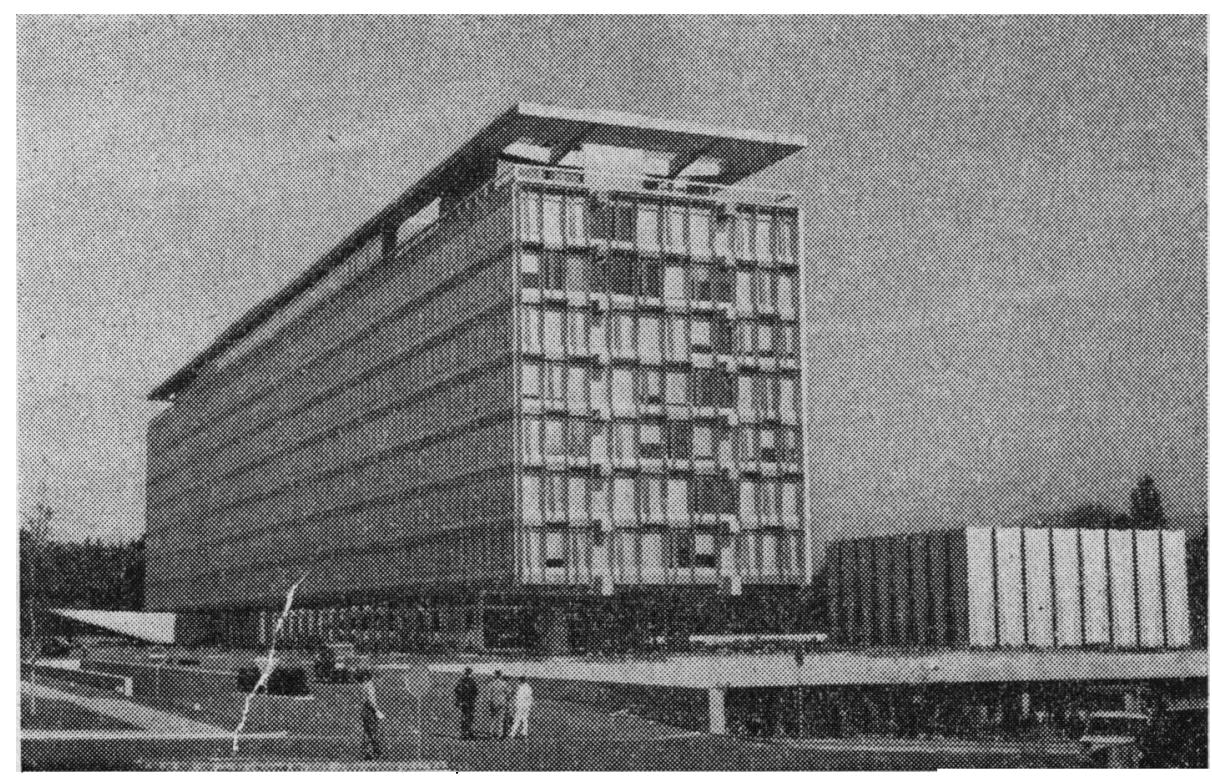

World Health Organization headquarters in Geneva. hygiene, sanitary education, and endemic diseases such as leprosy. Perhaps in competition with this organization, but ostensibly arising out of a recommendation of the eleventh Irternational Sanitary Conference 1903, there was established in Paris four years later the Office International d'Hygiène Publique (O.I.H.P.). This body had as its charter an agreement signed in Rome by 12 sovereign states. Although primarily concerned with quarantine and sanitary conventions, the office in the years between the two world wars enlarged its range of interest and studied, inter alia, biological standardization, hospital construction, and food hygiene.

\section{League of Nations}

To this pair of international health organizations there was added in 1921 the Health Organization of the League of Nations, which was the outcome of a clause in the covenant of the League welcoming the inclusion of a health organization within its administrative structure. Established in Geneva, it was at first overshadowed by the Office International d'Hygiène Publique. However, with a dynamic 'medical director, Dr. Louis Rajchman, it soon became equal in importance and influence and ultimately outstripped the Office in the catholicity of its interests. It also differed in undertaking a certain amount of field work. The annual budget of the League Organization never exceeded $£ 80,000$ and its dedicated permanent staff was always small in number. Considerable assistance, however, was given by commissions of experts and by short-term consultants. One of the first acts of the new organization was to establish itself as the weekly distrilutor of epidemiological information, using both Geneva and a special bureau in Singapore as collecting posts.

In parallel with this activity the Organization found itself involved in the urgent post-war situation created by epidemics of typhus in Poland and Eastern Europe. Later it undertook studies of world prevalence of other major communicable diseases-malaria, plague, tuberculosis, and trypanosomiasis. Thereafter it brought cancer and heart disease within its purview. It also established commissions on the classification of death and disease, biological standardization, medical educa-

- Formerly Chief Medical Officer, Ministry of Health. Chairman, Brecutive Board, World Health Organization (1957-8); president, 12th World Health Assembly (1959). 
tion, and the unification of pharmacopoeias. Housing and rural hygiene, subjects requiring studies in the field, were also tackled. Later again, in response to a request from the Assembly of the League itself, the Health Organization published in 1935 a report on the physiological bases of nutrition, which was quickly acclaimed as a classic.

But with the outbreak of war in 1939 only the Pan American Sanitary Organization was able to continue its work. The Paris Office closed down; a two-man nucleus of the League Organization never failed throughout the war to issue the Weekly Epidemiological Record, but on all else was virtually inactive. During the later stages of the war the health division of the United Nations Relief and Rehabilitation Administration (U.N.R.R.A.) filled the gaps to some extent. It was active in combating epidemics and in providing medical supplies. It was also an additional link between the past and the future.

\section{W.H.O. Established}

Such then was the situation when, at the end of the war, governments gathered together in San Francisco, established the United Nations, and promulgated its charter. At one stage there was a danger that health-as a matter of international concernmight only appear in the charter under the miscellaneous heading of "social matters." The vigorous intervention of the delegates of Brazil and China prevented this gaffe. At the instance of the Economic and Social Council, which is the United Nations' instrument responsible for "economic, social, cultural, educational, health and related matters," a preliminary technical committee of 18 members met in Paris in MarchApril, 1946.

This committee drew up the broad outline of the constitution of the proposed World Health Organization, described its operating principles with considerable eloquence, and defined its functions. These proposals were then brought before an international health conference in New York in June-July of the same year. The conference, which was representative of governments, concluded its proceedings on 19 July when the delegates of 61 states signed the constitution. Two of them acting on behalf of China and the United Kingdom were able to do so without reservation. The other 59 signed conditionally.

At the same time authority was given to establish an interim commission of 18 members. This body, with Dr. Brock Chisholm, of Canada, as executive secretary and a small staff, was to operate a world health programme as a matter of urgency until such time as 26 members of the United Nations had accepted the constitution and finally established the Organization. For one reason or another this twenty-sixth signature was

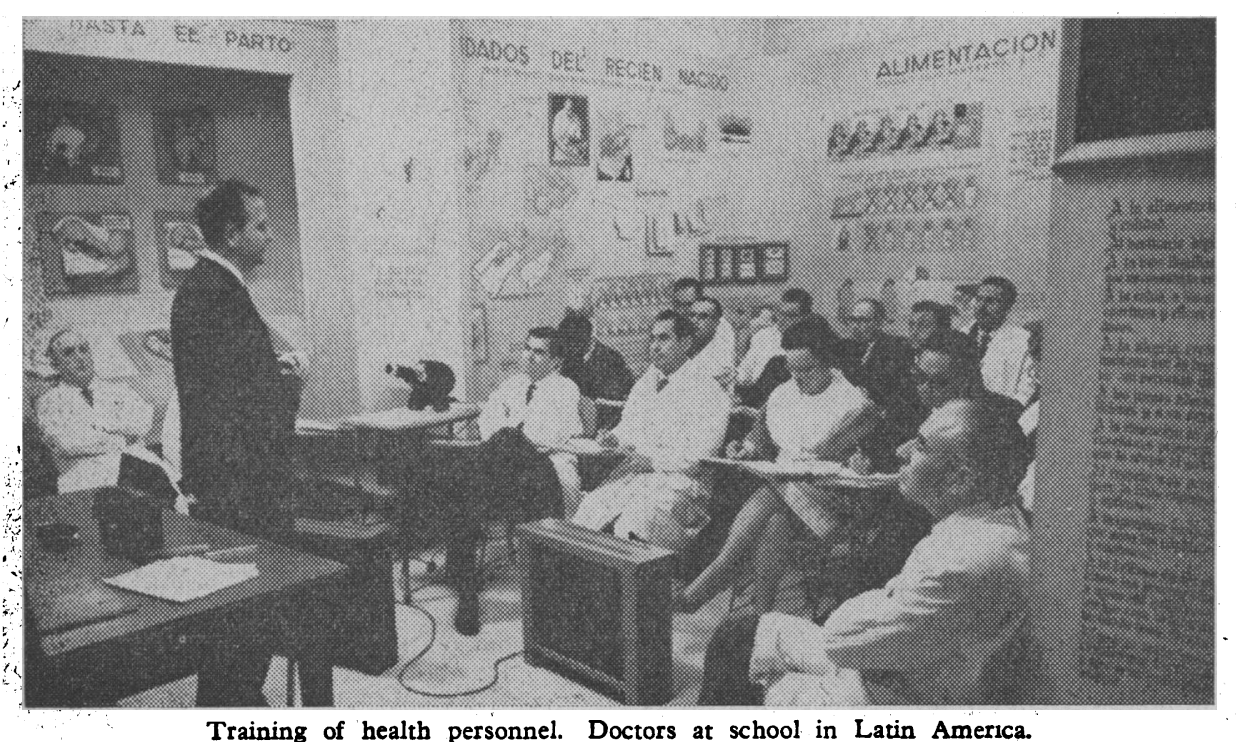

celebrated as W.H.O.'s birthday.

This year the twenty-first World Health Assembly meets in Geneva on 6 May. It will commemorate 20 years of work and achievement directed towards the overall objective of the Organization-" the attainment by all peoples of the highest possible levels of health."

As part of the reorganization which followed the establishment of W.H.O., both the Health Organization of the League and the Paris Office disappeared. U.N.R.R.A. also dissolved, leaving some of its assets to W.H.O. The Pan American Sanitary Organization, however, survived. Its historical status was preserved by an agreement that, while it would retain identity, resources, and name, the governing council and office should also act as the W.H.O. regional committee and Office for the Western Hemisphere.

One other question which exercised the Organization was the site of its permanent home. Paris, Geneva, Copenhagen, New York, even an English city were all considered, but ultimately Geneva was again selected as the headquarters of the world's international health organization.

\section{Machinery of Government}

It is impossible in this short paper to describe the administrative structure of W.H.O. in any detail. Suffice it to say that it is composed of three main organs-the World Health Assembly, the Executive Board, and the Secretariat. The Assembly is representative of governments and now includes 129 member states and associate members. It meets annually to formulate policy and establish the programme and budget for the next year. The Executive Board consists of 24 persons designated by as many member states. It is the executive arm of the Assembly. The Secretariat comprises the Director-General, Dr. M. G. Candau, who succeeded Dr. Brock Chisholm in 1953, and members of the technical and administrative staff. These now exceed 3,000 in number. About one-third are stationed in Geneva. The remainder work in the regional offices or on field assignments.

The headquarters in Geneva occupy a magnificent new building overlooking the lake. This is in effect the "power house" of the Organization. Here are located the technical units concerned with almost every kind of health activity and branch of the medical sciences. Alongside them are the administrative units with functions ranging from financial control to the production of W.H.O.'s many publications.

The work of W.H.O. is also decentralized to six regional offices-in Copenhagen, Brazzaville, New Delhi, Manila, and Washington. Each regional office has a regional director who is responsible to the DirectorGeneral and the regional committee for carrying out the various programmes. of the Organization. The regions are the "grass roots" of W.H.O., for it is to the regional office that governments bring their requests for assistance. This may take many forms-for example, a survey to assess needs, support of a malaria eradiction programme, advice on national health planning, or a group of training fellowships. Approved requests are incorporated in the region's annual programme, which in turn is included with the headquartiors requirements in the programme and budget which the Director-General submits to the World Health Assembly. 
The necessary funds for the regular budget are raised by precepts on the member states ranging from $0.04 \%$ of the total for many developing countries to $31 \%$ for the United States.

\section{Work of the Organization}

This in outline is the machinery of government of the Organization and its method of work. The work of the Organization derives primarily from the responsibilities inherited in 1946 from the League of Nations, the Paris Office, and U.N.R.R.A., but it has been increased by the development of new interests. The activities which were taken over included the epidemiological notification service, biological standardization, the classification of diseases and causes of death, and several of U.N.R.R.A.'s relief programmes dealing with communicable disease and nutrition. Later in 1948 a list of priorities was prepared. Malaria, maternal and child health, tuberculosis, venereal disease, nutrition and environmental sanitation were placed at the highest level. Public health administration, parasitic and virus diseases, and mental health followed in that order. Programmes were developed in all these fields. In addition use was made of some of the new weapons-B.C.G. vaccination, penicillin, and D.D.T.-in country-wide campaigns against tuberculosis, syphilis and yaws, and malaria. This system of priorities was soon supplemented by a more flexible approach which took account of the specific requests of governments for assistance, particularly for training facilities. Some regions, notably the European, with fewer development problems introduced programmes for such subjects as cancer, heart disease, and hospital administration.

\section{Extension of Interests}

Between 1948 and 1954 the Organization settled down. The budget rose from $\$ 5,000,000$ in 1948 to $\$ 8,500,000$ in 1954 ; the staff increased from 250 to 850 . In 1955 the idea of a worldwide campaign for the eradication of malaria was launched at the Assembly. By 1957 a malaria eradiction division was operating a programme with projects in over 50 countries, financed largely from a special voluntary fund. A dynamic attack on one of the world's greatest health problems was under way.

In 1958 at the tenth Anniversary Commemorative Meeting in Minneapolis, Dr. Milton Eisenhower, the personal representative of the President of the United States, proposed that the Organization, working with the world's leaders in medical research, should review its role in that field. The Organization had been a stimulator and co-ordinator of research-and not a doer. It should so continue, but with fuller effect and a wider horizon.

A year later, following upon this study, the Assembly authorized the Director-General to appoint an advisory committee on medical research composed of leading scientists, ordered a research programme for 1960 , and allocated an additional $\$ 500,000$ to initiate it. A voluntary fund was also established, to which over the next three years the United States Government contributed more than $\$ 2 \mathrm{~m}$.

In 1960 the U.N. and W.H.O. were faced with a serious emergency in the newly independent Republic of the Congo (Leopoldville). Owing to the political crisis the health situation had gravely deteriorated. W.H.O. demonstrated its co-ordinating and advisory functions in a variety of ways. It placed
37 Red Cross medical teams where they were most needed. By recruiting a few key health personnel it helped to avert the breakdown of environmental services and strengthened the control of disease. Finally, looking beyond the immediate present to the future staffing of the health services, it worked out a long-term programme of education and training of doctors and other personnel which is now bearing fruit. Altogether it was a highly successful reply to a challenge.

Another factor in increasing W.H.O.'s African responsibilities was the rapid accession of many states to independence, followed by their admission to the Organization as full members. At the end of 1960 only seven governments in the Africa Region were members of W.H.O. Five years later there were 27.

W.H.O.'s serious interest in national health planning can be traced to Latin American activities which began in 1959. It extended to the African Region in 1963, when the Organization became associated with the governments of five African countries in the preparation of health plans which were to be an integral part of the national plans for social and economic development. It is now an advisory activity of major importance.

Population problems in many parts of the world have been a major concern of the United Nations for several years, and their repercussions have affected W.H.O. They arise not only from population increase but are associated with urbanization, industrialization, and changes in the age structure of the population, and involve questions of family planning and human reproduction. This complex of difficult problems resulted in W.H.O. establishing a Human Reproduction Unit in 1965. About the same time the Assembly authorized the provision of technical advice on the subject to such member states as requested it.

This is only one example of the continuing extension of W.H.O.'s interests. Sometimes the activity is an entirely new venture, as with human reproduction and the even more recently created Division for Research in Epidemiology and the Communication Sciences. At other times it is a more vigorous and comprehensive attack on an old-standing health problem. Typical of this approach are the community water supply programme and the world-wide smallpox eradication campaign, both of which were launched in 1965.

\section{Measure of Achievement}

This brief summary of some of W.H.O.'s early commitments and more recently acquired responsibilities is an incomplete record, and can do no more than suggest the sum total of achievement.

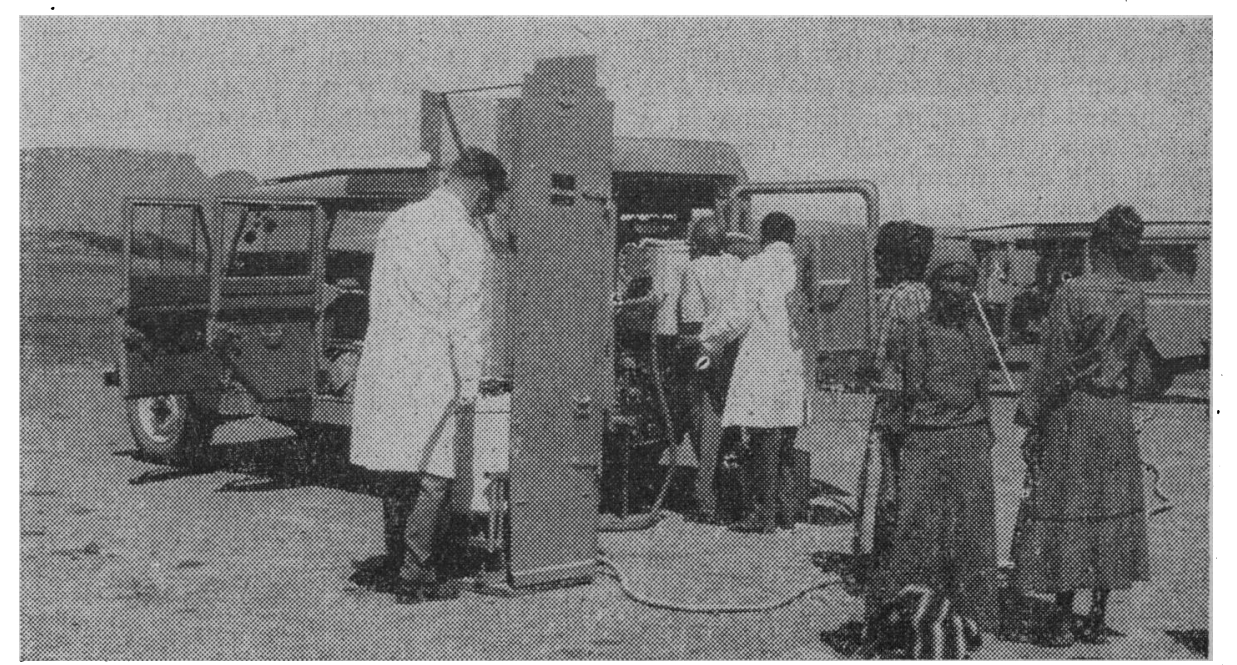

A W.H.O. mobile $x$-ray unt operating near a village on a high plateau in Basutoland. 
It is, as yet, difficult to measure that achievement in quantitative terms. Improved health statistics in many parts of the world are some indication of success, but the mere existence of a service or laboratory can also be evidence of an advance.

Nevertheless it is possible to recognize certain positive achievements. First among them is the universality of W.H.O. This is shown by its membership of 129 states. It is manifest in the system of regional offices serving as foci of advice and action. It is seen again in the network of reference laboratories and services for the collection of epidemiological data.

Next there are the results of the great campaigns against such diseases as malaria, yaws, and tuberculosis, which have saved innumerable lives, and been of immeasurable benefit to the economy of many developing countries.

There is the major contribution which has been made to educational activities of member governments in helping them to raise the total of nedical schools in their territories from 553 about 1950 to 717 in 1966. Another facet of this activity is the granting of fellowships to individuals, who now total some 3,500 each year.

The strengthening of health services, always one of W.H.O.'s primary functions, has extended into the planning of national health services as a concurrent and integral part of economic and social development. And at the local level the development of the basic health services idea is an equally great achievement.

Then there is the international co-ordination of medical research in certain fields, and the communication and sharing of the results.

Finally, though the list could be continued, there is the accomplished fact of getting the nations to work together.

All in all this amounts to an overall achievement of considerable magnitude of which the Organization, and not least its dedicated staff and inspiring Director-General, Dr. Candau, can well be proud.

Yet with all this great record of work done, W.H.O. cannot rest content. There is so much more to do.

\title{
CONFERENCES AND MEETINGS
}

\section{Scientific Basis of Drug Dependence}

\author{
[From a SPECIAL CORRESPONDENT]
}

A symposium on the Scientific Basis of Drug Dependence, organized by the Biological Council, was held at the Middlesex Hospital Medical School on 8 and 9 April 1968. Eighteen official bodies shared in its sponsorship, and papers ranged over every aspect of the drug-addiction problem and dealt with such apparently disparate approaches as looking at cellular chemistry, studying the morphine-dependent rat, clinical report, and epidemiological survey.

Professor I. ChIEN put forward a sociologist's view, and suggested that the function of a drug was more than its pharmacological action-a drug also had a symbolic meaning In so far as heroin-taking was conceived by society as " disreputable," it served to express hostility, and because it was disapproved of by orthodox society it could symbolize rebellion. Drug-taking symbolized a way of life dedicated to "bringing about a better world." $\mathrm{He}$ also advanced the view that becoming an addict could offer the young adolescent who felt himself lost and trampled upon in a society with which he could not compete a needed role and substitute social identitybeing a "junkie" was being someone.

The symbolic meaning of drug-taking was again discussed by Dr. C. R. B. JoYCE, who reviewed work on the placebo response and reported preliminary results of some collaborative research in which he and his colleagues had been examining the characteristics of patients who went to their general practitioners for repeat prescriptions. Among such patients there was an excess of people who had been widowed, and among those who turned to their doctors for repeat prescriptions of centrally acting drugs there was an excess of those who were divorced or separated.

Summarizing present knowledge on the pharmacological basis of tolerance and addiction, Professor W. D. M. Paton suggested that a theory based on the response of the host was now very much better supported than any hypothesis which sought to explain addictive phenomena on the basis of a drug having two opposed actions. He reviewed the experimental evidence which suggested that morphine, rather than blocking nerve conduction, inhibited acetylcholine release: for adrenergic transmitters the position was not so clear. Tolerance might be produced partly by a chemical " denervation hypersensitivity" and partly by transmitter surfeit, while withdrawal symptoms might be seen as the "bounce" of adaptive mechanisms.

The extent to which scientific study of fundamental biological aspects of drug dependence had been advanced in recent years was witnessed by papers at this symposium which dealt with such matters as receptor theory, the relation between brainprotein synthesis and analgesic tolerance, and the disposition and metabolism of morphine within the central nervous system.

Several papers dealt with the study of behavioural aspects of dependence in addicted animals, and Dr. G. A. Deneau showed a film made at the Southern Research Institute, Birmingham, Alabama, of the selfadministration of drugs by monkeys with indwelling venous catheters. An animal which had started taking an opiate never tired of drug-taking and never voluntarily came off the drug, while a monkey which was taking amphetamines did so frantically for some days and then, exhausted, desisted for a period-a finding inviting obvious human comparisons.

Several as yet unpublished epidemiological studies of drug-taking in Britain were reported, and Dr. N. H. RATHOD described investigations which he had undertaken of heroin abuse in Crawley New Town. He showed how an estimate of prevalence might be arrived at by a combination of cross-checking methods-by asking known addicts themselves for the names of drug-taking friends, checking with general practitioners, and looking for cases of jaundice among young people. His work suggested that any simple official figure on the number of heroin users in an area might be a considerable underestimate.

The proceedings of this meeting will be published in one volume by J. \& A. Churchill Ltd. 